\title{
Research in Home-Care Telemedicine: Challenges in Patient Recruitment
}

\author{
USHA SUBRAMANIAN, M.D., M.S., ${ }^{1-3}$ FAITH HOPP, Ph.D., ${ }^{4}$ JULIE LOWERY, Ph.D. ${ }^{4,5}$ \\ PETER WOODBRIDGE, M.D., M.B.A., ${ }^{1,2,6}$ and DAVID SMITH, M.D. ${ }^{2,3}$
}

\begin{abstract}
This study reports challenges in recruiting patients for a randomized controlled trial of homecare telemedicine. Descriptive statistics on patient eligibility for home-care telemedicine services and patient refusals for participation are provided. Frequency counts of reasons for study exclusion and participant refusal and Chi-square tests to compare race and age-related differences are given. Of 302 home-care patients reviewed, $197(65.2 \%)$ did not meet inclusion criteria. The most common reasons for study exclusion were patients either needing $<2$ visits per month $(n=59,30 \%)$ or $>3$ skilled nurse visits per week $(n=46,23.4 \%)$. Of the eligible patients $(n=105), 79$ persons $(75.2 \%)$ refused participation. The most common reasons for refusals were lack of perceived addition benefit of telemedicine ( $n=27,34.2 \%)$, and that routine health care was sufficient $(n=23,29.1 \%)$. Higher than expected proportions of patients did not meet chosen eligibility criteria or refused to participate. These results should be helpful in designing home-care telemedicine programs and clinical trials.
\end{abstract}

\section{INTRODUCTION}

A LTHOUGH THERE IS A LARGE DEMAND and reported increased patient satisfaction with home care, ${ }^{1,2}$ the cost-effectiveness of this care is controversial. ${ }^{3-5}$ Recently, home-care telemedicine has been reported as having the potential to influence processes and outcomes for care for home-care patients in addition to decreasing costs. ${ }^{6,7}$ Although trials of telephone-based telemedicine have been shown to be effective in certain clinical areas, ${ }^{8.9}$ there have been few randomized controlled trials evaluating the effectiveness of video-based technology. ${ }^{10,11}$ Moreover, there is little data on patient exclusions and refusals for these videobased trials. ${ }^{7}$

To determine the full potential of home telemedicine as a delivery mechanism for home-care services, and to guide researchers interested in conducting randomized trials in this area, more information is needed regard-

\footnotetext{
${ }^{1}$ Richard L. Roudebush VA Medical Center, Indianapolis, Indiana.

${ }^{2}$ Division of General Internal Medicine, Department of Medicine, Indiana University School of Medicine, Indianapolis, Indiana.

${ }^{3}$ Regenstrief Institute for Healthcare, Indianapolis, Indiana.

${ }^{4}$ Center for Practice Management and Outcomes Research, VA Ann Arbor Health Care System, Ann Arbor, Michigan.

${ }^{5}$ Department of Plastic Surgery, University of Michigan Medical School, Ann Arbor, Michigan.

${ }^{6}$ Department of Pathology and Laboratory Medicine, Indiana University School of Medicine, Indianapolis, Indiana.
} 
ing patient eligibility and patients' perceptions about these programs. ${ }^{6,12,13}$ This study reports the challenges faced in recruiting home-care patients into a randomized telemedicine trial. We present our 12-month interim results.

\section{METHODS}

The study is a randomized controlled trial conducted among home-based primary care (HBPC) patients at the Indianapolis VA Medical Center. Patients are randomized either to treatment (interactive video) or to control (usual HBPC).

Usual-care patients receive nursing services at home and periodic telephone contact with the clinical staff concerning their home-care services. Intervention group patients, in addition to receiving usual home-care services, have contact with the VA clinical staff using telemedicine units. The telemedicine equipment is an Aviva 1010 manufactured by American TeleCare Inc. Each unit is 16 inches wide, 13 inches deep, and 10 inches tall. The system requires a $110 \mathrm{~V}$ electrical regular phone line. The units have integrated voice, video, blood pressure cuff, and stethoscope. Peripheral attachments such as blood pressure cuff and stethoscope are not used by all patients. Each telemedicine unit consists of two components: a home unit with interactive video technology and peripheral attachments (such as blood pressure, stethoscope, and glucose monitor), and a central unit (base station) for the clinical provider. Patients are able to see the clinical staff members on the video monitor, and clinical staff members are able to see the patient at home. When the unit is turned off, there is no ability for clinical staff and patients to communicate. Intervention-group patients use the telemedicine units as a means of facilitating clinical contact and patient education services. For home-care visits where in-person contact is not required, and where deemed clinically appropriate, telemedicine visits are substituted for in-person visits.

To be eligible for the study, patients need to be enrolled in the HBPC program at the study site. In addition, eligible patients must have a record of high health-care services use in the previous year. This criterion was established because past use of health-care services has been shown to be the strongest predictor of future use, ${ }^{14-16}$ and because one of the goals of home telemedicine is to reduce the use of inpatient and outpatient services. Therefore, our inclusion criteria were those patients enrolled in the HBPC program who had at least: (1) six outpatient visits, one hospitalization, or two or more emergency room visits in the previous 12 months; (2) a care plan specifying two or more skilled nursing visits (SNV) per month; and (3) an expected need for future home care visits for at least 1 month.

The exclusion criteria were: (1) lack of a telephone; (2) having participated in a pilot study with telemedicine; (3) having a life expectancy of less than 6 months; (4) patients judged by home-care clinicians to be unable to use the telemedicine equipment (because of vision, hearing, and/or communication difficulties), or lacked caregiver support to operate the telemedicine equipment; and (5) patients needing more than three SNV per week. The Institutional Review Board approved the study protocol.

Using electronic medical records, the study coordinator reviewed all patients enrolled in the Indianapolis HBPC program for possible inclusion. For eligible patients, the study coordinator contacted the clinical nurse to rule out possible reasons for exclusion. When no exclusion criteria were identified, all eligible patients were initially contacted by telephone to set up an appointment to discuss study participation. During this conversation, the research assistant briefly explained that a study is being conducted involving the use of telemedicine equipment, and encouraged patients to set up an appointment to learn more about the equipment and to consent to study participation. For patients who did not refuse participation after the phone call, the coordinator scheduled a home visit. During this visit, the coordinator explained more details of the study by reviewing the consent form, which describes the randomization process, all study procedures, the risks and benefits of participation, confidentiality rights, and personnel to contact for additional information. Patients were also given printed educational material regarding the use 
of the technology as well as a practical demonstration. Those who agreed to participate are enrolled. The research office staff created sequentially numbered, sealed, opaque envelopes containing randomized assignments to treatment or control groups. Patients were aware of assignment after randomization was complete.

Patients who refused study participations were asked their reasons for refusal. The study coordinator recorded these patient refusal responses. Following the first year of the study, the recorded responses were reviewed and 15 categories were derived. Two investigators independently assigned responses to these categories. A third investigator collated the assignment and resolved discrepancies with a consensus meeting with the other two investigators. When the home care staff did not identify a medical condition that would preclude use of the telemedicine equipment, but the patient indicated such a condition as a reason for nonparticipation, they were coded as having refused participation.

\section{RESULTS}

The descriptive characteristics of all homecare patients reviewed for the study are presented in Table 1. Between September, 2001, and October, 2002, 302 HBPC patients were reviewed, who were predominantly male $(98.0 \%)$, white $(61.6 \%)$, with a mean age of 69.9 years $(\mathrm{SD}=12.8)$. Among patients reviewed $(n=302), 197(65.2 \%)$ patients were excluded because they did not meet one or more of the inclusion criteria. Among the remaining patients $(n=105), 79(75.2 \%)$ declined to participate in the trial, and only $26(24.7 \%)$ were enrolled. A comparison among persons excluded, refusing participation, and participants revealed no significant age differences $(\mathrm{F}=1.28$; $\operatorname{Pr}>\mathrm{F}=0.28$ ) or racial differences between Caucasians and African-Americans (Chi Sq $1.58 ; p=0.45$ ) among the three groups. All of the women reviewed $(n=6)$ were excluded as none of them met inclusion criteria. Because no women were approached for study participation, there were insufficient numbers to permit a valid statistical analysis of gender by group. Although we did not have data that would directly allow for comparison of enrolled, excluded, and refusal patients on socioeconomic status, data on enrolled patients in the study provided some information on this demographic variable. Specifically, roughly onethird of patients enrolled in the study during 2001-2002 ( $n=8 / 26 ; 30.8 \%)$ were classified as having met the VA means test requirement for care, suggesting that a substantial number of these patients had low socioeconomic status (SES).

The number of patients in each of the exclusion categories is presented in Table 2. Of the 197 patients meeting exclusion criteria, most were excluded for three reasons: 59 (30.0\%) because they were receiving less than two visits per month; $46(23.3 \%)$ were receiving more than three skilled visits per week; and 48 (24.4\%) were discharged from HBPC prior to study solicitation.

The number of patients in each of the refusal categories is presented in Table 3. Of the patients meeting eligibility $(n=105), 79(75.2 \%)$ declined study participation. Among 79 patients who refused study participation, $n=47$ refused at first telephone contact and $n=32$ refused at the in-person home visit. The four most common reasons for refusal were (1) lack of perceived benefit of telemedicine $(n=27$;

Table 1. Outcomes for Patients Reviewed for Study

\begin{tabular}{lcccc}
\hline Categories & $\begin{array}{c}\text { Number } \\
(\%)\end{array}$ & $\begin{array}{c}\text { Age } \\
\text { (mean, SD) }\end{array}$ & $\begin{array}{c}\text { Gender } \\
(\% \text { male })\end{array}$ & $\begin{array}{c}\text { Race } \\
(\% \text { white })\end{array}$ \\
\hline $\begin{array}{l}\text { Total home-care patients reviewed } \\
\text { Patients not meeting inclusion criteria }\end{array}$ & 302 & $69.9(12.8)$ & 98.0 & $61.6 \%$ \\
$\quad($ excluded) & $197(65.2)$ & $69.0(12.9)$ & 97.0 & $63.4 \%$ \\
$\begin{array}{l}\text { Patients meeting inclusion criteria } \\
\text { Patients refusing to participate }\end{array}$ & $105(34.7)$ & $71.5(12.4)$ & 100.0 & $57.1 \%$ \\
Patients enrolled $^{\mathrm{a}}$ & $79(75.2)$ & $71.6(13.2)$ & 100.0 & $55.7 \%$ \\
\hline
\end{tabular}

aAmong those meeting inclusion criterion $(n=105)$. 
Table 2. Reasons for Study Exclusion $(n=197)$

\begin{tabular}{lll}
\hline Categories for exclusion $^{\text {a }}$ & $\mathrm{n}$ & $\%$ \\
\hline $\begin{array}{l}\text { < visits/month as part of home care } \\
\quad \text { plan }\end{array}$ & 59 & 30.0 \\
>3 SNV per week & 46 & 23.3 \\
$\begin{array}{l}\text { Discharged prior to study solicitation/ } \\
\quad \text { less than } 30 \text { days in home care }\end{array}$ & 48 & 24.4 \\
$\begin{array}{l}\text { Patient already has been in study (pilot) } \\
\quad \text { and/or telemedicine equipment }\end{array}$ & 23 & 11.7 \\
$\quad$ from other programs & & \\
$\begin{array}{l}\text { No phone or unreliable phone } \\
\text { Patient does not meet high resource }\end{array}$ & 15 & 7.6 \\
$\quad$ utilization criterion & 14 & 7.1 \\
$\begin{array}{l}\text { Less than } 6 \text { months life expectancy } \\
\text { Unable to use equipment as reported }\end{array}$ & 3 & 1.5 \\
$\quad$ by nurse & 2 & 1.0 \\
\end{tabular}

andividual patients can be coded in more than one exclusion category. Therefore, the total numbers are greater than the number of patients.

$34.2 \%)$; (2) perceptions that existing health-care routines were sufficient $(n=23 ; 29.1 \%)$; (3) perceptions that the equipment would be burdensome or bothersome ( $n=15 ; 19.0 \%)$; and (4) an unwillingness to become involved in anything else $(n=14 ; 17.7 \%)$.

We also analyzed the refusal reasons separately by method of refusal (phone vs. in-person refusals). Persons who refused on the phone were somewhat more likely to indicate that they felt their existing health care was sufficient $(n=$ $17 ; 36.2 \%$ of phone refusals) compared with those who refused in person $(n=6 ; 18.8 \%$ of inperson refusals). Persons refusing by phone were also somewhat more likely to indicate that participation would be a bother or burden $(n=$ $10 ; 21.3 \%)$ compared with those refusing in person $(n=5 ; 15.6 \%)$. However, because of the small numbers within each refusal category, these should be interpreted as trends rather than definitive, and the numbers within each refusal category were not sufficient to test for association using Chi-squared analysis.

\section{DISCUSSION}

Home-care telemedicine is a promising method for improving access to care among rural and urban populations, particularly vulnerable populations. Currently there is lack of information regarding persons who are most likely to benefit from telemedicine. In addition, there is little information about patients' perceptions about telemedicine, which may influence the application of this technology.

This study has a number of implications for the use of appropriate inclusion and exclusion criterion for home-care telemedicine programs. Results from the first 12 months of our study indicate that roughly 1 of 5 patients $(n=48$; $24.4 \%$; Table 2), were discharged from the home-care program shortly after entering or had expected home-care enrollment of less than 1 month, a pattern similar to patients admitted to long-term care. ${ }^{17}$ Because of the time and cost involved with equipment setup, patients with an expected longer term in homecare programs should be the targets of future recruitment efforts for home telemedicine technology.

Patients receiving three or more hands-on visits per week ( $n=56 ; 23.3 \%$; Table 2$)$ were excluded from our study, because we did not anticipate that they would benefit from the addition of telemedicine. However, we have since learned that home telemedicine can provide a needed and useful component of patient education for clinical applications such as in wound care. Also, some initial ineligibility criteria may be modified with some creative effort, such as securing a telephone for patients who do not have telephone service. In this study, our focus for the intervention was on persons who had high resource utilization, and only a small proportion of home-care patients $(n=14,7.1 \%)$ were not high resource users. Further research is needed to determine if the high resource utilization observed in this population can be lowered by the use of home telemedicine services.

The refusal rates in our study $(75.2 \%$, Table 1) were higher than those reported in other studies. A home telemedicine randomized trial of chronic heart failure $(\mathrm{CHF})$ patients had a $5.6 \%$ refusal rate (19 patients not willing to be evaluated out of 339 patients with a verified primary admission diagnosis of $\mathrm{CHF}$ ), ${ }^{18}$ whereas a randomized study of hypertensive patients using nonvideo (store and forward) monitoring of blood pressure found that only $20.3 \%$ of those identified by physicians as possible study candidates (34/167) either did not 
Table 3. Patients' Reported Reasons for Refusal $(n=79)$

\begin{tabular}{|c|c|c|c|c|c|c|}
\hline \multirow[b]{3}{*}{ Categories for refusal ${ }^{\text {a }}$} & \multicolumn{6}{|c|}{ Mode of refusal } \\
\hline & \multicolumn{2}{|c|}{$\begin{array}{c}\text { Total } \\
(\mathrm{n}=79)\end{array}$} & \multicolumn{2}{|c|}{$\begin{array}{l}\text { Phone } \\
(\mathrm{n}=47)\end{array}$} & \multicolumn{2}{|c|}{$\begin{array}{l}\text { In person } \\
(\mathrm{n}=32)\end{array}$} \\
\hline & $\mathrm{n}$ & $\%$ & $\mathrm{n}$ & $\%$ & $\mathrm{n}$ & $\%$ \\
\hline $\begin{array}{l}\text { Patient not able to understand how equipment } \\
\text { would benefit him/her. Does not see the need } \\
\text { for equipment. }\end{array}$ & 27 & 34.2 & 14 & 29.8 & 13 & 40.6 \\
\hline $\begin{array}{l}\text { Patient perceives that their existing health-care } \\
\text { routine is sufficient. }\end{array}$ & 23 & 29.1 & 17 & 36.2 & 6 & 18.8 \\
\hline $\begin{array}{l}\text { Patient feels equipment would be a bother or } \\
\text { burden. Does not want more equipment, or to } \\
\text { bother with it. }\end{array}$ & 15 & 19.0 & 10 & 21.3 & 5 & 15.6 \\
\hline $\begin{array}{l}\text { Patient does not want to become involved with } \\
\text { anything else. Too busy, not home. }\end{array}$ & 14 & 17.7 & 9 & 19.2 & 5 & 15.6 \\
\hline $\begin{array}{l}\text { Patient perceives that he/she does not have } \\
\text { appropriate space. Indicates that clutter, poor } \\
\text { lighting, lack of available outlets, and/or other } \\
\text { unsafe conditions will make participation } \\
\text { difficult. }\end{array}$ & 7 & 8.9 & 3 & 6.4 & 4 & 12.5 \\
\hline $\begin{array}{l}\text { Patient reports expectation of being discharged } \\
\text { soon. }\end{array}$ & 7 & 8.9 & 3 & 6.4 & 4 & 12.5 \\
\hline $\begin{array}{l}\text { Patient is fearful of losing in-person home } \\
\text { nursing visits if they are enrolled in the } \\
\text { telemedicine program. }\end{array}$ & 5 & 6.3 & 5 & 10.6 & 0.0 & 0.0 \\
\hline $\begin{array}{l}\text { Patient perceives that they would not be able to } \\
\text { hear, or communicate over equipment. }\end{array}$ & 5 & 6.3 & 5 & 10.6 & 0.0 & 0.0 \\
\hline $\begin{array}{l}\text { Patient reports having medical condition that } \\
\text { will make it difficult for him/her to use the } \\
\text { equipment. }\end{array}$ & 4 & 5.1 & 3 & 6.4 & 1 & 3.1 \\
\hline $\begin{array}{l}\text { Patient reports expecting to move, and/or have } \\
\text { temporary housing. }\end{array}$ & 3 & 3.8 & 1 & 2.1 & 2 & 6.3 \\
\hline Patient provides no reason but refuses & 2 & 2.5 & 2 & 4.3 & 0 & 0.0 \\
\hline Patient does not want to participate in research & 2 & 2.5 & 0 & 0.0 & 2 & 6.3 \\
\hline $\begin{array}{l}\text { Patient doesn't think he/she could remember } \\
\text { how to use it. Doesn't understand how to } \\
\text { operate equipment. }\end{array}$ & 1 & 1.3 & 1 & 2.1 & 0 & 0.0 \\
\hline $\begin{array}{l}\text { Patient does not trust housemates. Doesn't } \\
\text { want to be responsible for equipment. }\end{array}$ & 1 & 1.3 & 0 & 0.0 & 1 & 3.1 \\
\hline Patient reports being afraid to try new things & 1 & 1.3 & 0 & 0.0 & 1 & 3.1 \\
\hline
\end{tabular}

${ }^{a}$ Individual patients can be coded in more than one Refusal Reason category. Therefore, the total numbers are greater than the number of patients. 
attend their scheduled study appointment or declined participation in the trial. ${ }^{19}$ A study involving a diverse group of home-care patients similar to those in our program did not identify the numbers of patients who refused to participate, making comparisons between our study and similar work difficult. ${ }^{7}$ Among those who refused in our study, very few $(n=2$; $2.5 \%$, Table 3) specifically mentioned an unwillingness to participate in research as a reason for refusal. This suggests that reasons for refusal in our study are unlikely to be directly related to the randomized nature of the study design.

There are several possible reasons for a higher rate of study refusal in this study compared with previous work. First, the prospective study participants lived in a metropolitan area with many available medical care services. Quite possibly, a more rural population, with less access to medical care and ongoing homecare services would perceive a greater potential benefit of telemedicine. Second, it was common for patients to indicate that they did not perceive a benefit from telemedicine $(n=$ 27; $34.2 \%$; Table 3) or to express the belief that existing services were sufficient $(n=23 ; 29.1 \%$; Table 3). Previous research suggests that greater experience with telemedicine technology leads to higher patient acceptance of this mode of care. ${ }^{20,21}$ In a recent study of patient attitudes toward use of telemedicine at home among participants in a study of pressure ulcer monitoring, $37 \%$ of study participants queried at the beginning of the study felt that home-care telemedicine was not better than recovering in the hospital or an extended-care facility and a similar number were unsure that a physician could provide care for them via telemedicine. After three visits of telemedicine data collection, there was a marginally significant $(p=0.08)$ increase in patients' ratings of the quality of home-care telemedicine compared to in-person physician visits. ${ }^{23}$ These findings suggest that after gaining some familiarity with the telemedicine equipment, patients' acceptance of the technology increased. These results further emphasize the need for significant efforts in research and practice on patient education programs regarding homecare telemedicine. ${ }^{22,23}$

Several limitations of the present study should be noted. First, VA patients are different from other patient groups in terms of background and demographic characteristics (Table 1 ), and these differences make generalizations to other home care groups difficult. ${ }^{24}$ Second, this study was conducted at a single site, a factor that limits the generalizability of our results. It is significant to note, however, that many of the home-care patients met the VA means test requirement, indicating that they had incomes below the poverty line. Future research, based on a greater variety of sites, should be helpful in further determining the experience of other low-income home-care populations with telemedicine technology. Last, the first year of the study was a time during which telemedicine technology was relatively new to both homecare staff members and home-care patients. More established programs, where telemedicine is perceived as an integral part of patientcare services, may possibly be more successful in recruiting potential participants.

Home telemedicine is a potentially promising technology for home-care patients. However, there are certain challenges that should be recognized. Our experience suggests that home-care programs should carefully consider inclusion/exclusion criteria relevant to their program and operations. Like previous programs, ${ }^{18}$ we found it necessary to revise this criterion as the program progressed so that patients who were likely to benefit from the technology could be targeted. Yet, a large number of patients were either ineligible for home telemedicine or gave reasons for choosing not to participate in the study. Few patients gave a reluctance to participate in research as a reason for refusal, suggesting that many patients will refuse to participate in home telemedicine programs even when active research is not part of the program. These results indicate that home care programs need to carefully consider how many patients are most likely to benefit from this technology. Practitioners should also anticipate the need to educate patients on the benefits of this new technology and to respect and consider in advance their patient's willingness to participate. Both anticipated patient eligibility, as well as anticipated patient acceptance, should inform home telemedicine program development. 


\section{ACKNOWLEDGMENTS}

This work was supported by grant number VA HSRD—Tel: 20015-1. The authors wish to thank other study staff involved in data collection, including Aaron Goldsmith (M.S.W.), Theresa Bubenzer (R.N.), and Heather Wallace (B.A.). Carla Anderson (R.N., M.S.N.), director of the home-care program, provided needed clinical expertise in the design and development of the program.

\section{REFERENCES}

1. Cummings JE, Hughes SL, Weaver FM, et al. Costeffectiveness of Veterans Administration hospitalbased home care. A randomized clinical trial. Arch Intern Med 1990;150:1274-1280.

2. Keysor JJ, Desai T, Mutran EJ. Elders' preferences for care setting in short- and long-term disability scenarios. Gerontologist 1999;39:334-344.

3. Wilson JR, Smith JS, Dahle KL, et al. Impact of home health care on health care costs and hospitalization frequency in patients with heart failure. Am J Cardiol 1999;83:615-617, A10.

4. Kemper P. The evaluation of the national long-term care demonstration: Overview of the findings. Health Serv Res 1988;23:161-173.

5. Weissert WG. The National Channeling Demonstration: What we knew, know now, and still need to know. Health Serv Res 1988;17:174-187.

6. Allen A, Doolittle G, Boysen C, et al. An analysis of the suitability of home health visits for telemedicine. I Telemed Telecare 1999;5:90-96.

7. Johnston B, Weeler L, Deuser J, Sousa KH. Outcomes of the Kaiser Permanente tele-home health research project. Arch Fam Med 2000;9:40-45.

8. Balas EA, Jaffrey F, Kuperman GJ, et al. Electronic communication with patients: Evaluation of distance medicine technology. I Am Med Assn 1997;278:152-159.

9. Friedman RH, Kazis RE, Jette A, et al. A telecommunications system for monitoring and counseling patients with hypertension. Impact on medication adherence and blood pressure control. Am J Hypertens 1996;9(4 Pt 1):285-292.

10. Grigsby et al. Effects and effectiveness of telemedicine. Health Care Financ Rev 1995;17:115-131.

11. Telemedicine for the Medicare Population. Summary, Evidence Report/Technology Assessment: Number 24. AHRQ Publication Number 01-E011, February 2001. Agency for Healthcare Research and Quality, Rockville, MD. http://www.ahrq.gov/clinic/epcsums/ telemedsum.html

12. Whitten P, Collins B, Mair F. Nurse and patient reac- tions to a developmental home telecare system. I Telemed Telecare 1998;4:152-160.

13. Whitten P, Mair F, Collins B. Home telenursing in Kansas: patients' perceptions of uses and benefits. I Telemed Telecare 1997;3(Suppl 1):67-69.

14. Coleman E, Wagner E, Grothaus L, Hecht J, Savarino J, Buchner D. Predicting hospitalization and functional decline in older health plan enrollees: Are administrative data as accurate as self-report? I Am Geriatr Soc 1998;46:419-425.

15. Smith D, Norton J, Roberts S, et al. Unexpected hospital admissions among patients with diabetes. Mellitus. Arch Intern Med 1983;143:41-47.

16. Wolinsky F, Culler S, Callahan CM, Johnson R. Hospital resource consumption among older adults: a prospective analysis of episodes, length of stay, and charges over a seven year period. L Gerontol 1994;49: S240-S252.

17. Spillman BC, Lubitz J. New estimates of lifetime nursing home use: have patterns of use changed? Med Care 2002;40:965-975.

18. Jerant AF, Azari R, Nesbitt TS. Reducing the cost of frequent hospital admissions for congestive heart failure: a randomized trial of a home telecare intervention. Med Care 2001;39:1234-1245.

19. Rogers MA, Small D, Buchan DA, et al. Home monitoring service improves mean arterial pressure in patients with essential hypertension. A randomized, controlled trial. Ann Intern Med 2001;134:1024-1032.

20. Demiris G, Speedie S, Finkelstein S. A questionnaire for the assessment of patients' impressions of the risks and benefits of home telecare. L Telemed Telecare 2000; 6:278-284.

21. Demiris G, Speedie SM, Finkelstein S. Change of patients' perceptions of TeleHomeCare. Telemed $J e$ Health 2001;7:241-248.

22. Krousel-Wood MA, Re RN, Abdoh A, et al. The effect of education on patients' willingness to participate in a telemedicine study. L Telemed Telecare 2001;7: 281-287.

23. Lowery JC. Pressure ulcer assessment via telemedicine: Final report for HSR\&D. Washington, DC, VA HSR\&D, 2002.

24. Zemencuk JK Feightner JW, Hayward RA, Skarupski KA, Katz SJ. Patients' desires and expectations for medical care in primary care clinics. I Gen Intern Med 1998;13:273-276.

Address reprint requests to: Dr. Usha Subramanian HSRD 11-H

Roudebush VA Medical Center 1481 West 10 Street Indianapolis, IN 46202

E-mail: usubrama@iupui.edu 
This article has been cited by:

1. Walter Palmas, Jeanne Teresi, Philip Morin, L. Thomas Wolff, Lesley Field, Joseph P. Eimicke, Linnea Capps, Alejandro Prigollini , Irma Orbe, Ruth S. Weinstock, Steven Shea . 2006. Recruitment and Enrollment of Rural and Urban Medically Underserved Elderly into a Randomized Trial of Telemedicine Case Management for Diabetes CareRecruitment and Enrollment of Rural and Urban Medically Underserved Elderly into a Randomized Trial of Telemedicine Case Management for Diabetes Care. Telemedicine and e-Health 12:5, 601-607. [Abstract] [PDF] [PDF Plus] 